\title{
DIAGNOSTIC ASSESSMENT OF STUDENTS' MISCONCEPTIONS ABOUT HEAT AND TEMPERATURE THROUGH THE USE OF TWO-TIER TEST INSTRUMENT
}

\author{
Eric Appiah-Twumasi ${ }^{*}$, Daniel $\mathrm{Nti}^{2}$, Richard Acheampong ${ }^{3}$ and Frederick Ameyaw ${ }^{4}$ \\ ${ }^{1}$ Akenten Appiah-Menka University of Skills Training and Entrepreneurial Development, \\ Ghana. \\ ${ }^{2}$ Presbyterian Women College of Education, Ghana \\ ${ }^{3}$ Berekum College of education, Ghana \\ 4Bagabaga College of Education, Ghana \\ *Corresponding author: appiatumasi@gmail.com
}

\begin{abstract}
Cite this article:
Eric A., Daniel N., Richard A., Frederick A. (2021), Diagnostic Assessment of Students' Misconceptions about Heat and Temperature Through the Use of Two-Tier Test Instrument. British Journal of Education, Learning and Development Psychology 4(1), 90-104. DOI: 10.52589/BJELDPO22B5EPK
\end{abstract}

\section{Manuscript History \\ Received: 10 May 2021 \\ Accepted: 31 May 2021 \\ Published: 12 June 2021}

Copyright $\odot 2020$ The Author(s) This is an Open Access article distributed under the terms of Creative Commons AttributionNonCommercial-NoDerivatives 4.0 International (CC BY-NC-ND 4.0 ), which permits anyone to share, use, reproduce and redistribute in any medium, provided the original author and source are credited.
ABSTRACT: The research looked into the misconceptions held by Physics students about some selected heat and temperature concepts. The research design employed in this study was a diagnostic-descriptive research design. A sample of 56 Senior High School (SHS) two (2) students, drawn from Berekum Senior School in the Berekum Municipality, Ghana, were used for the study. An instrument known as the Two-Tier Test Instrument of Heat and Temperature Concepts (HTCT) was employed in data gathering. Mean score, standard deviation, frequencies, percentage were used to answer research questions one and two, while one-way multivariate analysis of covariance (MANCOVA) and correlational analysis were used to answer research question three. Results indicated that students used for this study hold misconceptions, lack understanding, and have difficulties explaining the selected heat and temperature concepts used in the HTCT instrument. The results also revealed that misconceptions about heat and temperature concepts non-significantly interact with student age $(F .545=.463, p>.05)$, but significantly interact with students' gender $(F 4.541=.038, p<.05)$. Based on the results obtained, the researchers recommended the use of two-tier test instruments and advanced organisers to identify students' misconceptions of scientific concepts.

KEYWORDS: Misconception, Understanding, Temperature, Advanced Organiser, Heat. 


\section{INTRODUCTION}

Science educators have widely recognised the importance of student's misconception in the learning process of science because of its effects on students' understanding. Misconceptions are non-scientific thoughts held by students about a specific concept and are caused primarily by students' misunderstanding of the subject, resulting from students' prior experiences. Different terms like alternative conceptions, pre-scientific conceptions, and misconceptions have been used to describe different forms of students' prior understanding of ideas and conceptual difficulties (Gurel \& Erylmaz, 2015). Misconceptions are formed when a learner's prior knowledge required for processing new information is not well articulated due to the poor bridging, which results in confusion and poor reasoning (Hanflawed Sam \& Antwi, 2012). Consequently, students' prior knowledge is an essential factor in successful transitional learning since learning can occur in classrooms and be carried out in the students' immediate environment, resulting in initial ideas before formal schooling.

Senior High School students are required to achieve maximum learning goals in developing the skills to conceptual understanding and think creatively by studying every problem that occurs in their life using appropriate physics concepts (Collins \& Olson, 2014; Barrow, 2015). However, sometimes, students' prior knowledge interferes with formalised learning of physics concepts. This results in inappropriate explanations of physics concepts. For example, students' difficulty understanding the concepts of heat and temperature has led to misconceptions of these two concepts.

Consequently, misconceptions about heat and temperature are found to be common in Senior High School students. In particular, Fries-Gaither (2009) stated that students might hold a variety of misconceptions about heat, temperature and energy. Given its importance, some science educators have researched misconceptions in the und erstanding of heat and temperature concepts for a long time (example: Gonen \& Kocakaya, 2010; Pathare \& Pradhan, 2010; Alwan, 2010). Specifically, Gonen and Kocakaya (2010) stated that student conception and misconceptions on heat and temperature were acquired and stored and occurred without an ostensible link between everyday life and school experiences. Gonen and Kocakaca (2010) found that forty-one per cent $(41 \%)$ of the students sampled for a study had misconceptions on heat and temperature. They concluded that students response to all questions on heat and temperature showed a general misunderstanding of ideas related to thermal equilibrium, heat transfer and temperature concept.

In a related study, Pathare and Pradhan (2010) indicated that most of the students used for their study on heat and temperature reported that heat increases the temperature of a body. Their results also revealed that some of the students conceive heat as the energy content of the system and seem to equate heat with internal energy. Moreover, concerning thermal conductivity, none of the students showed awareness that heat might lead to external work, and most of the students seemed to equate the internal energy of a system with the system's total energy. However, on the concept of latent heat, Pathare and Pradhan (2010) reported that most of the respondents answered that the boiling point of water would remain constant even after the gas stove is turned on to a higher flame, with few exceptions going for increased temperature misconception. Similarly, Alwan (2010) designed a diagnostic assessment to determine students' misconception about heat and temperature. Alwan's findings revealed that most of the students used for the study held alternative conceptions of heat and temperature. 
Based on this background, the researchers designed this two-tier test instrument to explore Senior High Schools students' misconceptions about heat and temperature, using research subjects from Berekum Municipality in the Bono Region of Ghana.

\section{Statement of the Problem}

According to Hanson et al. (2012), students either consciously or subconsciously construct their concepts as explanations for the behaviours, properties or theories they experience. Students believe that most of these explanations are correct because they make sense in terms of their understanding of the world's behaviour around them.

It is very significant to determine students' misconceptions in heat and temperature concepts just like any other concepts in physics. However, literature searches have revealed that there has been no study conducted in Ghana, especially in the Berekum Municipality Senior High School students' assessing students' misconceptions about heat and temperature and suggesting ways teachers of physics should use to expel these miscomputations. Hence, the present study examines some misconceptions held by students in some selected concepts in heat and temperature and subsequently suggests possible ways to overcome this scientific learning barrier.

\section{Objectives of the Study}

This study is concerned with students' misconceptions about heat and temperature. The specific objectives of the study are:

1. To determine misconceptions students encounter in learning some selected concepts of heat and temperature.

2. To analyse the extent of students' difficulties in learning some selected heat and temperature concepts.

3. To examine students' biographical variables (age, gender, and HTCT score) on students' misconceptions in heat and temperature concepts.

The following research questions were formulated as a guide for data collection and analysis based on the objectives stated.

\section{Research Questions}

What misconceptions do students hold about heat and temperature concepts?

1. What misconceptions do students hold about heat and temperature concepts?

2. To what extent are students' misconceptions about heat and temperature concepts exposed through the use of the Two-Tier Test Instrument?

3. To what extent do students' biographical variables such as age, gender, and HTCT scores interact to produce students' misconception about heat and temperature concepts? 


\section{THEORETICAL UNDERPINNING AND RELATED LITERATURE REVIEW}

\section{Formation of Student's Misconceptions}

According to Mensah and Quorcoo-Nelson (2017), physics educators have used a model termed constructivism to help understand students' learning. The theoretical underpinning of constructivism research comes from several sources, including David Ausubel and L. S. Vygotsky. David Ausubel and L. S. Vygotsky's early work in constructivism research focused on identifying students' conceptions about scientific phenomena and how those students' conceptions differ from accepted scientific conceptions (Mensah \& Quorcoo-Nelson, 2017).

In constructivism learning theory, students' construction of knowled ge begins at an early age so that by the time child ren encounter formalised study of science, they have developed stable and highly personal conceptions for many natural phenomena (Mensah \& Quorcoo-Nelson, 2017). As children learn about the world around them formally through classroom education or informally through children's everyday experiences, they often tend to form their views or understanding of the world around them.

This concept formation implies that in any science education, the socio-cultural environment of the students plays an essential role in their concept formation. Reason being that the unscientific explanations of concepts and unscientific interpretations that students acquire from their encounter outside the classroom constitute their personal and cultural knowledge that students used as background to evaluate, interpret phenomenon and expertise that they encounter in the science classroom (Mchombo, 2016). Therefore, students' socio-cultural acquisition of knowledge enables students to solve problems in their everyday life and make sense of the world through a personal process in which sensory data are given meaning in terms of prior knowledge.

Many previous studies have given credence to students' prior existing knowledge before formal education. For example, Valanides (2000) found that students bring ideas into the classroom, which differ from those accepted by the scientific community. According to Asara-Gaison (2010), some of the ideas the children have developed are well-rooted in his/her culture, traditions and religion, and this creates conflict in his/her mind as he/she encounters Science classroom. The author added that this puts the school-going child in a dilemma due to two seemingly opposing beliefs: science and tradition/culture, resulting in the formation of a misconception of scientific concepts.

Henriques (2002) maintained that whether or not children previously have some knowledge and scientific concepts before entering into formal education are no longer essential as the science education community generally accepts the idea that children enter the classroom with their understanding of the world. What is important to note, according to Black and Lucas (1993), is first, that this knowledge can affect children's school learning of science.

\section{Causes of Students Misconceptions}

Several studies have revealed many causes of students' misconceptions. For instance, students' everyday life experiences out of the classroom, including using words and specific terms in a non-scientific context, confuses students. This may lead to students' misconceptions. Schmidt (1998) noted that scientific terms that are used in different contexts, because the se terms have shifted their meaning during the historical development are also a possible cause of students' 
misconception in science. Extensive studies in the student's misconceptions by Pathare and Pradhan (2010) revealed some common likely causes as follows:

Presumed ideas: Most students have some presumed models formed even before they encounter a scientific notion.

Language and metaphor: Students' daily engagements and conversation with peers gives rise to many students' alternative concepts about a particular phenomenon. According to Pathare and Pradhan (2010), a word/phrase which means one thing in daily dialect may mean something else in scientific language.

Conceptual difficulties: The difficulties arise because some concepts are not directly agreeable to experience. Such concepts are constructs and, therefore, non-intuitive. Sometimes, students fail to understand the limitations of using a concept or a law and hence students over-generalise.

Teacher driven factors: In the typical science classroom, the teacher is viewed as ultimately having authority on the subject. Therefore, students' explanation of concepts given by a teacher is accepted without question. According to Pathare and Pradhan (2010), one reason for this is the driven examination system, where students' memorisation of concepts and recalling skills are overemphasised. Also, teachers sometimes often fail to give students an overview of the topic necessary for understanding it because of limited time. All of these according to Pathare and Pradhan may lead to the formation of students' misconceptions, which are different from the relevant scientifically accepted concepts.

Similarly, in an attempt to identify factors contributing to students' misconceptions, Erman (2016) found that the leading causes of students' misconceptions were incomplete information on concepts, difficulty understanding basic concepts, and lack of effective communication among students and teachers. Erman's results suggest that teachers should identify students' misconceptions before teaching any concepts and fundamentally facilitate effective communication to correct any misconceptions held by students.

\section{Using Diagnostic Assessments Tools to identify Students' Misconception}

According to Taboola (n.d.), diagnostic assessments in teaching and learning were adapted from the medical discipline. Taboola added that in medicine, diagnostic assessment means identifying disease by employing a patient's medical history and conditions. For example, when a patient comes to a medical practitioner, the medical practitioner initially asks the patient some questions to gather helpful information about the disease and then uses other techniques and tools to get more relevant information to identify the disease and its possible cause(s).

Similarly, in the domain of education, diagnostic assessment has many equally important applications. For example, students' difficulties in learning physics frequently occur, with all students, at all levels, among students of all school-going age, and both high and low mental ability. Accordingly, teachers use a diagnostic assessment to aid the determination of such learning difficulties. Diagnostic assessment is used in teaching and learning when teachers want to adjust teaching, and it plays a significant role in improving learning outcomes for all students. According to Betts, Hahn and Zau (2011), diagnostic assessment assesses what the learner already knows, the nature of difficulties that he/she has, which might limit their engagement in new learning if undiagnosed. 
Teachers are continuously making decisions about individual or group of students in achieving learning objectives. The implication is that teachers should examine multiple forms of data, including past experiences, attitudes, learning styles, interest, strengths and weakness, reasons for referral, and conduct interviews with parents (Barr, Blachowicz, Katz, Kaufman, 2013). Therefore, the effectiveness of any teaching and learning process depends on the teacher's understanding of the learners' level of mastery of the subject area, and it is achieved through diagnostic assessments.

\section{Methodology}

This section describes the methodology used to conduct the study. It includes research design, population and sampling procedures, research instruments, validity and reliability of research instruments. Data collection procedures and data analysis procedures are also discussed in this section.

\section{Research Design}

A diagnostic-descriptive research design was adopted in this study to explore Senior High School students' misconception about heat and temperature. The researchers intended to diagnose students' misconceptions about heat and temperature concepts and subsequently described the extent of the misconception that students hold concerning the concepts under consideration.

\section{Participants}

A purposive sampling technique was used to select a school in the Berekum Municipality from the three Senior High School, where students pursue science as an elective course. Purposive sampling is a non-probability sampling technique where samples are chosen by intentionally seeking individuals or situations likely to provide a greater understanding of a chosen concept of research (Sarantakos, 2005).

Similar to Sarandakos's definition of purposive sampling, the researchers interacted with the physics teachers in the three science schools in the Berekum Municipality with the mind of identifying which physics teachers had treated the concepts of heat and temperature under consideration with their students. The interaction revealed that out of the three Senior High Schools in the Berekum Municipality, only physics teachers of Berekum Senior High School had treated the concepts of heat and temperature concepts with their students. Hence, students from the Berekum Senior High School were purposely selected for the study.

Specifically, fifty-six (56) students comprised of male and female final year science students of Berekum Senior High School in the Berekum Municipality were used for the study. Table 1.0 shows the gender and age distribution of respondents. It is observed from Table 1.0 that the respondents have a higher male population than the female population. Out of a total number of fifty-six (56) respondents, 28(50.00\%) were males while their female counterparts were $28(50 \%)$ with age $(\mathrm{M}=16.21, \mathrm{SD}=1.42, \mathrm{Mim}=14$, Max 19) distributions of participants. 


\section{Research Instrument}

A researcher developed two-tier multiple-choice Heat and Temperature Concept Test (HTCT), composed of 10-questions with reliability (r) of 0.72 using test-retest, which was used to collect data. This was used to diagnose students' misconceptions in heat and temperature concepts. Two physics educators validated the test items at the Berekum College of Education Science Department.

\section{Structure of the Two-Tier Test Instrument (HTCT)}

The HTCT was a self-constructed test instrument. The nature of the two-tier test instrument required the respondents to answer a multiple-choice question on heat and temperature and then justify their responses by telling why they selected that response to each question. The questions were made of measurement of temperature and the effect of temperature changes on objects. A section of HTCT was on the quantity of heat given out or absorbed and the physical changes due to heat transfer. Also, questions on the natural mode of heat transfer were part of the HTCT instrument. Table 1.0 shows the detailed structure of the HTCT.

\section{0: Detail Structure of the Heat Temperature Concepts Two-Tier Test Instrument*}

\begin{tabular}{clc}
\hline S/N & \multicolumn{1}{c}{ Tier-One } & Tier-Two \\
\hline $\mathbf{1}$ & $\begin{array}{l}\text { Will a cup of hot chocolate stay hot longer if you place a lid on it } \\
\text { (Yes/No)? }\end{array}$ & Why \\
$\mathbf{2}$ & $\begin{array}{l}\text { Could heat travel through solid by convection? (Yes/No). } \\
\text { To heat a pot of water to boil, is it more effective to apply the heat at the } \\
\text { bottom of the pot or the top (Bottom/Top). }\end{array}$ & $\begin{array}{l}\text { Explain } \\
\text { Explain }\end{array}$ \\
$\mathbf{4}$ & $\begin{array}{l}\text { If a student wants to heat a pot of water as fast as possible in the } \\
\text { laboratory, would you recommend to him or her to heat it half full or } \\
\text { full? (Half full/full). }\end{array}$ & Explain \\
$\mathbf{5}$ & $\begin{array}{l}\text { If you take a bite of hot meat pie, the tomato sauce is more likely to } \\
\text { burn your mouth than the crust (True / False). }\end{array}$ & Explain \\
$\mathbf{6}$ & $\begin{array}{l}\text { Energy from the sun warms your face. Does it travel to your face by } \\
\text { conduction, convection or radiation? }\end{array}$ & Explain \\
$\mathbf{7}$ & $\begin{array}{l}\text { A rock heat by the sun is thrown into the ocean. The temperature of the } \\
\text { rock drops. Does the temperature of the ocean rise? (Yes/No). }\end{array}$ & Explain \\
$\mathbf{8}$ & $\begin{array}{l}\text { Suppose you live in a hot desert climate. What colour would you paint } \\
\text { your house? (White/Black). }\end{array}$ & Explain \\
$\mathbf{9}$ & $\begin{array}{l}\text { Suppose you live in a hot desert climate. What colour would paint your } \\
\text { solar hot-water collector? (White/Black). }\end{array}$ & Explain \\
$\mathbf{1 0}$ & $\begin{array}{l}\text { Winds blowing across the ocean have less temperature difference than } \\
\text { winds blowing across a desert (True/False). }\end{array}$ & Explain \\
\hline
\end{tabular}

*Total score of HTCT is 20 Marks. 


\section{Scoring of the Two-Tier Test Instrument}

In tier-one, if a student selects the correct answer, and in the second tier subsequently makes a correct explanation, then the said student is considered as having the correct understanding of the concept as conveyed in the question. Similarly, if a student selects the wrong answer due to misconception in tier-one, and explains this wrong answer with reasons as if it is the correct answer, then the said student can be considered a misconception as expressed in the question (Kanli, 2015).

\section{Data Analysis}

Descriptive statistics of percentages were used to analyse the misconceptions in the respondents' responses, while multivariate analysis of covariance (MANCOVA) was used to test the interaction between gender, age, and misconception of students in the heat-temperature concepts.

\section{RESULT OF THE STUDY}

Research Question 1: What misconceptions do students hold about heat and temperature concepts?

The misconception students hold on the heat and temperature concept (HTCT) was analysed using descriptive statistics. The analysis was done on each of the three concepts (temperature, heat transfer and heat capacity) and presented in Tables 2-4 to ascertain a fair idea of how their misconceptions run through these concepts. A summary of the level of students' understanding of the various concepts (temperature, heat transfer and heat capacity) are presented in Tables $2-4$.

Table 2.0: Level of Students' Misconception on Temperature (T)

\begin{tabular}{|c|c|c|c|c|c|}
\hline Ques & Items & Answer & $\begin{array}{c}\% \\
\text { correct }\end{array}$ & $\begin{array}{c}\% \\
\text { wrong }\end{array}$ & Misconception \\
\hline 7 & $\begin{array}{l}\text { A rock heated by the sun is } \\
\text { thrown into the ocean. The } \\
\text { temperature of the rock drops. } \\
\text { Does the temperature of the } \\
\text { ocean rise? }\end{array}$ & Yes & 19.64 & 80.35 & $\begin{array}{l}\text { The size of the stone and } \\
\text { its temperature are too } \\
\text { small to influence the } \\
\text { temperature of the ocean. }\end{array}$ \\
\hline 8 & $\begin{array}{l}\text { Suppose you live in a hot } \\
\text { desert climate. What colour } \\
\text { would you paint your house? }\end{array}$ & White & 32.14 & 66.07 & $\begin{array}{l}\text { Colour has no effect on } \\
\text { the absorption and } \\
\text { radiation of heat. }\end{array}$ \\
\hline 9 & $\begin{array}{l}\text { Suppose you live in a hot } \\
\text { desert climate. What colour } \\
\text { would paint your solar hot- } \\
\text { water collector? }\end{array}$ & Black & 17.86 & 82.14 & $\begin{array}{l}\text { Colour has no effect on } \\
\text { the absorption and } \\
\text { radiation of heat. }\end{array}$ \\
\hline
\end{tabular}


Percentages observed in Table 2 indicate students' understanding and level of misconception students hold on the concept of temperature. A very high percentage of students had the answers to tier-one questions wrong with questions 7 and 9 recording the highest (80.35 and 82.14 respectively) percentages. Answers to the second-tier questions uncovered students' misapprehensions about temperature since, in most cases, response to tier two is dependent on tier one.

Table 3.0: Level of Students' Misconception on Heat Transfer (HT)

\begin{tabular}{|c|c|c|c|c|c|}
\hline Ques & Items & Answer & $\begin{array}{c}\% \\
\text { correct }\end{array}$ & $\begin{array}{c}\% \\
\text { Wrong }\end{array}$ & Misconception \\
\hline 1 & $\begin{array}{l}\text { Will a cup of hot } \\
\text { chocolate stay hot longer } \\
\text { if you place a lid on it }\end{array}$ & No & 16.07 & 83.92 & $\begin{array}{l}\text { Once the hot chocolate } \\
\text { is kept in a cup with a } \\
\text { lid there will be no heat } \\
\text { loss. }\end{array}$ \\
\hline 2 & $\begin{array}{l}\text { Could heat travel } \\
\text { through solid by } \\
\text { convection? }\end{array}$ & No & 28.57 & 71.42 & $\begin{array}{l}\text { Medium facilitate heat } \\
\text { transfer, not } \\
\text { considering the type of } \\
\text { medium }\end{array}$ \\
\hline 3 & $\begin{array}{l}\text { To heat a pot of water to } \\
\text { boil, is it more effective } \\
\text { to apply the heat at the } \\
\text { bottom of the pot or the } \\
\text { top }\end{array}$ & Bottom & 41.07 & 58.92 & $\begin{array}{l}\text { Boiling occurs at the } \\
\text { top surface, therefore } \\
\text { supplying heat at the } \\
\text { top makes it more } \\
\text { effective. }\end{array}$ \\
\hline 4 & $\begin{array}{l}\text { If a student wants to heat } \\
\text { a pot of water as fast as } \\
\text { possible in the } \\
\text { laboratory, would you } \\
\text { recommend to him or } \\
\text { her to heat it half full or } \\
\text { full? }\end{array}$ & Half & 14.28 & 85.71 & Fair idea \\
\hline 6 & $\begin{array}{l}\text { Energy from the sun } \\
\text { warms your face. Does it } \\
\text { travel to your face by } \\
\text { conduction, convection } \\
\text { or radiation }\end{array}$ & Radiation & 33.93 & 66.07 & $\begin{array}{l}\text { Perception is that the } \\
\text { air (gas) is acting as a } \\
\text { medium }\end{array}$ \\
\hline
\end{tabular}

In Table 3, most students again had tier-one answers wrong $(\mathrm{Q} 1=83.92 \%, \mathrm{Q} 2=71.42 \%$, $\mathrm{Q} 3=58.92 \%, \mathrm{Q} 4=85.71 \%$ and $\mathrm{Q} 6=66.07 \%$ ). However, it is interesting to note that a high percentage of students had tier-one of question 4 wrong, yet they seem to have a fair understanding of the concept. 
British Journal of Education, Learning and Development Psychology

ISSN: 2682-6704

Volume 4, Issue 1,2021 (pp. 90-104)

www.abjournals.org

Table 4.0: Level of Students' Misconception on Heat Capacity (HC)

\begin{tabular}{|c|c|c|c|c|c|}
\hline Ques & Items & Answer & $\begin{array}{c}\% \\
\text { Correc } \\
\text { t }\end{array}$ & $\begin{array}{l}\% \\
\text { Wron } \\
\text { g }\end{array}$ & Misconception \\
\hline 5 & $\begin{array}{l}\text { If you take a bite of hot } \\
\text { meat pie, the tomato } \\
\text { sauce is more likely to } \\
\text { burn your mouth than the } \\
\text { crust }\end{array}$ & True & 19.64 & 80.35 & $\begin{array}{l}\text { The sauce is found in the } \\
\text { crust and must have the } \\
\text { same temperature. Not } \\
\text { looking at their specific } \\
\text { heat capacities }\end{array}$ \\
\hline 10 & $\begin{array}{l}\text { Winds blowing across } \\
\text { the ocean have less } \\
\text { temperature difference } \\
\text { than winds blowing } \\
\text { across a desert }\end{array}$ & True & 14.07 & 85.71 & $\begin{array}{l}\text { The ocean and the desert } \\
\text { are all exposed to the sun } \\
\text { and must all have the } \\
\text { temperature }\end{array}$ \\
\hline
\end{tabular}

With no exception, Table 4 also recorded the highest number of students (Q5=80.35\% and Q10 $85.71 \%$ ) getting tier-one wrong which is reflected in tier two, showing that a majority of students have misconceptions in these concepts.

Research Question 2: To what extent are students' misconceptions about heat and temperature concepts exposed through the use of the Two-Tier Test Instrument?

Descriptive analysis was performed on students' responses to the THCT instruments. The results are presented in Table 5.

Table 4: Descriptive Analysis of the THCT

\begin{tabular}{lccccc}
\hline & & \multicolumn{2}{c}{ Tier-One } & \multicolumn{2}{c}{ Tier-Two } \\
\hline HTCT & Ques. & Correct* $^{*}$ & Wrong & Correct & Wrong \\
\hline Temperature(T) & $\mathbf{7}$ & $11(19.64)$ & $45(80.35)$ & $5(8.92)$ & $51(91.08)$ \\
& $\mathbf{8}$ & $18(32.14)$ & $37(66.07)$ & $9(16.07)$ & $47(83.93)$ \\
& $\mathbf{9}$ & $10(17.86)$ & $46(82.14)$ & $3(5.36)$ & $53(94.64)$ \\
Heat Transfer (HT) & $\mathbf{1}$ & $9(16.07)$ & $47(83.92)$ & $6(10.71)$ & $50(89.30)$ \\
& $\mathbf{2}$ & $16(28.57)$ & $40(71.42)$ & $3(5.36)$ & $53(94.64)$ \\
& $\mathbf{3}$ & $23(41.07)$ & $33(58.92)$ & $4(7.14)$ & $52(92.86)$ \\
& $\mathbf{4}$ & $8(14.28)$ & $48(85.71)$ & $4(7.14)$ & $52(92.86)$ \\
& $\mathbf{6}$ & $19(33.93)$ & $37(66.07)$ & $6(10.71)$ & $50(89.30)$ \\
Heat Capacity (HC) & $\mathbf{5}$ & $11(19.64)$ & $45(80.35)$ & $5(8.92)$ & $51(91.08)$ \\
& $\mathbf{1 0}$ & $8(14.07)$ & $48(85.71)$ & $7(12.50)$ & $49(87.50)$ \\
\hline
\end{tabular}

*Percentage in parenthesis.

Questions 7, 8, and 9 assessed the extent of students' understanding of temperature concepts. As shown in Table 5, the results revealed extensive students' difficulties with the temperature concepts in tier-one and tier-two. Specifically, in tier-one, 45, 37 and 46 out of 56 students had questions 7 , 
8 , and 9 wrong, with corresponding percentages of $80.35 \%, 66.07 \%$, and $82.14 \%$, respectively. In tier-two questions 7,8 , and 9, students were asked to explain the options selected in tier-one and revealed extensive misconceptions and lack of understanding of these concepts. 51(91.08\%), $47(83.93 \%)$ and $53(94.93 \%)$ out of the 56 students could not justify their answers or gave alternative explanations to questions 7, 8, and 9, respectively. As presented in Table 5, the few students scoring questions 7,8 and 9 on temperature concepts indicate the extent of students' difficulty or misconception about temperature concepts assessed in these areas.

Questions 1-4, and 6 assessed the extent of students' understanding of heat transfer. In tier one, as many as $47(83.92 \%), 40(71.42 \%), 33(58.92 \%), 48(85.71 \%)$, and $37(66.07 \%)$ students respectively had questions 1-4 and 6 wrong. Also, in the tier-two of 1-4, and 6 questions, 50(89.30\%), $53(94.64 \%), 52(92.86 \%), 52(92.86 \%)$, and 50(89.30\%) respectively could not justify their selected options to the questions or gave alternative explanations to the questions on transfer under consideration. Similarly, the few students presented in Table 5 scoring question s 1-4 and 6 on heat transfer and heat capacity concepts indicate the extent of students' difficulty or misconception in these areas.

Also, questions 5 and 10 assess students' understanding of specific heat capacity. As presented in Table 5, the results show students difficulty and lack of understanding in these areas. Specifically, $45(80.35 \%)$ and $48(85.71 \%)$ relative to questions 5 and 10 had these questions wrong. Also, in tiertwo of the same questions, as huge as 51(91.08\%) and 49(87.50\%) could not ex plain or justify their answers or gave alternative explanations to the concepts under consideration. Similarly, the few students presented in Table 5 scoring questions 5 and 10 relatives to specific heat capacity concepts indicate the extent of students' difficulty or misconceptions in these concepts.

Research Question Three: To what extent do students' biographical variables such as age, gender, and HTCT scores interact to produce students' misconception in heat and temperature concepts?

One-way multivariate analysis of covariance (MANCOVA) was used to examine the interaction between the variables. Students' total marks were denoted as the dependent variable, age as a covariate and gender as a categorical variable. The result of the analysis is shown in Table 5.

Table 6: Interaction between Age, Gender and Students Misconceptions on HTCT

\begin{tabular}{llccccc}
\hline Source & $\begin{array}{l}\text { Dependent } \\
\text { Variable }\end{array}$ & $\begin{array}{c}\text { Type III Sum } \\
\text { of Squares }\end{array}$ & Df & Mean Square & F & Sig. \\
\hline Corrected & Marks & $3.641^{\mathrm{a}}$ & 1 & 3.641 & .545 & .463 \\
Model & Gender & $1.086^{\mathrm{b}}$ & 1 & 1.086 & 4.541 & .038 \\
Intercept & Marks & 12.223 & 1 & 12.223 & 1.830 & .182 \\
& Gender & .004 & 1 & .004 & .018 & .894 \\
Age & Marks & 3.641 & 1 & 3.641 & .545 & .463 \\
& Gender & 1.086 & 1 & 1.086 & 4.541 & .038 \\
Error & Marks & 360.573 & 54 & 6.677 & & \\
Total & Gender & 12.914 & 54 & .239 & & \\
& Marks & 4242.000 & 56 & & & \\
\hline Corrected & Gender & 140.000 & 56 & & & \\
Total & Garks & $\mathbf{3 6 4 . 2 1 4}$ & $\mathbf{5 5}$ & & & \\
\hline
\end{tabular}

a. $\mathrm{R}$ Squared $=.010$ (Adjusted R Squared $=-.008$ )

b. $\mathrm{R}$ Squared $=.078$ (Adjusted R Squared $=.060$ ). 
It can be inferred from Table 6 that students' marks (students' misconceptions on heat and temperature concepts), non-significantly interact with student age $(F .545=.463, p>.05)$, but significantly interact with students' gender $(\mathrm{F} 4.541=.038, \mathrm{p}<.05)$. Thus, per the results obtained, a significant difference was detected between males and females (Males, $M=8.75$, $\mathrm{SD}=2.67$; Females, $\mathrm{M}=8.00, \mathrm{SD}=2.37$ ) on their misconception about heat and temperature concepts (See Table 7).

\section{Table 7: Descriptive Statistics of Gender}

\begin{tabular}{cccc}
\hline Gender & Mean & $\mathrm{N}$ & SD \\
\hline Male & 8.75 & 28 & 2.68 \\
Female & 8.00 & 28 & 2.37 \\
\hline Total & $\mathbf{8 . 3 7}$ & $\mathbf{5 6}$ & $\mathbf{2 . 5 3}$ \\
\hline
\end{tabular}

However, a non-interaction among students of different ages (see Table 6) was observed. Furthermore, because gender negatively correlates significantly with marks (students' misconceptions) ( $\mathrm{r}=.-149, \mathrm{p}>.05)$, it can be inferred that male and female students' misconception about heat and temperature concepts were affected by students' gender, $\mathrm{p}<.05$ (See Table 7).

\section{Table 7: Correlations among Variables.}

\begin{tabular}{|c|c|c|c|c|}
\hline \multirow{3}{*}{ Marks } & & Marks & Gender & Age \\
\hline & Pearson & 1 & -.149 & .068 \\
\hline & Sig. (1-tailed) & & .136 & .309 \\
\hline \multirow{4}{*}{ Gender } & $\mathrm{N}$ & 56 & 56 & 56 \\
\hline & Pearson & -.149 & 1 & .279 \\
\hline & Sig. (1-tailed) & .136 & & $.019 *$ \\
\hline & $\mathrm{N}$ & 56 & 56 & 56 \\
\hline \multirow[t]{3}{*}{ Age } & $\begin{array}{l}\text { Pearson } \\
\text { Correlation }\end{array}$ & .068 & $.279^{*}$ & 1 \\
\hline & Sig. (1-tailed) & .309 & .019 & \\
\hline & $\mathrm{N}$ & 56 & 56 & 56 \\
\hline
\end{tabular}

*. Correlation is significant at the 0.05 level (1-tailed).

\section{DISCUSSION OF RESULT}

A quick view of the two-tier test instrument administered to the participants showed that students hold misconceptions about temperature-related concepts. Specifically, the results presented in Tables 2-4 show very high percentages of students' misconceptions about heat and temperature concepts. Answers to the tier-two questions exposed students' misconceptions about heat and temperature concepts that were scientifically incorrect. 
The summary of students' misconceptions in heat and temperature concepts shows the percentage of students who had the various items wrong emanating from their misconceptions. The majority of students had questions 9 and 7 wrong from the data, recording the highest percentage of 82.14 and 80.35 , respectively. However, participants had a fair idea of questions $6,7 \& 8$. Though abysmally low, comparatively, students performed better on all the three questions set under temperature.

Similarly, participants' misconception on heat transfer was no exception. Questions 4 and 1 recorded the highest percentage (85.7 and 83.92) of students who had these questions wrong. Question 3 recorded the lowest of all, with a percentage of 58.92 students having it wrong. Misconception on the heat capacity concept test (HCT) also came to bear as participants displayed a high level of poor conceptual understanding, resulting in 85.71 per cent of students getting question wrong and 80.35 per cent of students getting question 10 wrong. Altogether, student's poor performance on Heat Temperature Concept Test (HTCT) is a result of their conceptual beliefs (misconceptions) that resulted in confusion and poor reasoning (Hanson, Sam \& Antwi, 2012).

To assess whether students' biographical variables such as age, gender and students' misconceptions interact, a one-way multivariate analysis of covariance (MANCOVA) was used to examine the interaction between the variables. Students' total marks were denoted as the dependent variable, age as a covariate and gender as a categorical variable.

The MANCOVA results show students' misconception about heat and temperature concepts non-significantly interact with student their age $(\mathrm{F} .545=.463, \mathrm{p}>.05)$, but significantly interact with their gender $(\mathrm{F} 4.541=.038, \mathrm{p}<.05)$. Thus, per the results obtained, a significant difference was observed between males and females (Males, $\mathrm{M}=8.75, \mathrm{SD}=2.67$; Females, $\mathrm{M}=8.00, \mathrm{SD}=2.37 ; \mathrm{F} 4.541=.038, \mathrm{p}<.05)$ on their misconception about heat and temperature concepts. The findings indicate that students' gender interactions influence students' misconceptions about heat and temperature concepts while students' ages do not.

\section{Instructional Implications of Results Obtained}

Students' misconceptions about heat and temperature concepts can be persistent and tough to correct. However, well-designed teaching instructions strategies could help students' misconceptions change to an accurate scientific understanding of heat and temperature concepts. For example, with the appropriate assessment strategy and advanced organisers, teachers can correct students' misconnections about heat and temperature.

Each diagnostic assessment probe to uncover students' alternative ideas in heat and temperature is crucial for correcting students' held misconceptions in heat and temperature. Also, teachers' application of diagnostic assessment in teaching and learning plays a significant role in improving learning outcomes for all students.

Moreover, advanced organisers are a crucial educational tool for teachers to understand and help students retain and remember new materials (Long-Crowell, 2014) and expel deep-rooted misconception. According to Long-Crowell (2014), advanced organisers provide a structure for students' thinking. He added that advanced organisers act as a conceptual bridge from the old information, making it easy for students to connect from one concept to the following concepts. Physics teachers can use advanced organisers to introduce their lessons and illustrate 
the relationship between what the students are about to learn and the information they have already learned

Therefore, if physics teachers use advanced organisers to associate the new information with old information of students, they could help students expel any misconception they have concerning the current topic understudied. Moreover, when students' prior knowledge is activated, they are likely to bring relevant knowledge to the learning situation to facilitate integrating the new concepts. Through the advanced organisers, students may bring deeprooted misconceptions that could hinder sound scientific understanding.

\section{RECOMMENDATION}

The researchers recommend that physics teachers who want to explore their students' misconceptions about heat and temperatures concepts should use two-tier instruments and advanced organisers that the researchers' thought as having effects on helping to explore students' misconceptions. The researchers also recommend that physics teachers use modern pedagogical instructional strategies to exploit students' prior knowledge and identify students' misconceptions. This new learning approach should pay more attention to helping students to build scientific thought and analysis also.

\section{REFERENCES}

Alwan, A. A. (2010). The misconception of heat and temperature Among physics students. Procedia Social and Behavioural Sciences, 12 (2011) 600-614.

Asare-Gaison, T. K. (2010). The influence and effects of religious and traditional belief systems on students' learning of science: A case study at Sefwi Wiawso community Junior High School. Master of Philosophy in Science Education Unpublished Thesis, University of Education, Winneba.

Barrow, R. (2015). Understanding skills: Thinking, feeling, and caring. New York: Routledge.

Black, P. J., \& Lucas, A. M. (1993). Children's Informal Ideas in Science. London- New York: Routledge.

Collins, J. A., \& Olson, I. R. (2014). Knowledge is power: How conceptual knowledge transforms visual cognition. Retrieved from https://www.ncbi.nlm.nih.gov.pmc.articles/PMC4090304

Erman, E. (2016). Factors contributing to students' misconceptions in learning covalent bonds. Retrieved from https://doi.org/10.1002/tea.21375

Fries-Gaither, J. (2009, March 12). Common misconceptions about heat and insulations. Retrieved from http:cadrek12.org/resources/publications/common-misconceptions-heatand-inslutions

Gurel, D. K., \& Erylmaz, A. (2015). A review and comparison of diagnostic instruments to identify students' misconceptions in science. Eurasia Journal of Mathematics, Science \& Technology Education, 11(5), 989-1008. 
Hanson, R., Sam, A., \& Antwi, V. (2012). Misconceptions of undergraduate chemistry teachers about hybridisation. African Journal of Educational Studies in Mathematics and Sciences, 10, 45-54.

Henriques, L. (2010, March 17). Children's ideas about the weather: A review of the literature. Retrieved from https://doi.org/10.1111/j.1949-8594.2002.tb18143.x

Kanli, U. (2015). Using a two-tier test to analyse students' and teachers' alternative concepts in Astronomy. Science Education International, 26(2),148-165.

Long-Crowell, E. (2014). Advance organizers in the classroom teaching: Strategies and advantages. Retrieved from http://www.education-

portal.com/academy/lesson/advanced-organizers-in the classroom-teaching-strategiesadvanges.html\#lesson

Lucariello, J., \& Naff, D. (2010). How do I get my students over their alternative conceptions(misconceptions) for learning? Retrieved from $\mathrm{https//www.apa.org/education/k12/misconceptions}$

Mchombo, S. (2016). Language, scientific knowledge, and the "context of learning" in African education. In Z. Babaci-Wilhite, (eds) Human Rights in language and STEM education (pp. 129-150). Rotterdam: Sense Publishers.

Mensah, F., \& Quorcoo-Nelson, R. (2017). Principles \& methods of teaching SHS physics. Cape Coast: Hampton Press Ltd.

Pathare, S., \& Pradhan, H. C. (2010). Students' misconceptions about heat transfer mechanism and elementary kinetics theory. Physics Education, 45(6), 629-634.

Sarantakos, S. (2005). Data that permit the establishment of role or causal relationships. Palgrave: Macmillan Hampshire.

Schmidt, H. (1998). Students' misconceptions-looking for a pattern. Retrieved from https:d oi.org/10.1002/ (SICI) 1098-237X (199704)81:2<123: AID-SCE1>3.0.CO;2-H

Taboola. (n.d). Diagnostic test: Concept, construction and barriers in statistics. Retrieved from https://www.yourarticlelibrary.com/statistics-2/diagnostic-test-conceptconstruction-and-barriers-statistics/92543

Valanides, N. (2000, October 1). Primary student teachers' understanding of the process and effects of distillation. Retrieved from https://d oi:10.1039/A9RP90032B 